\title{
Scripting Hate Crimes: Victim, Space and Perpetrator Defining Hate
}

By: Andrew R. Spieldenner, Cerise L. Glenn

\section{This is an Author's Accepted Manuscript of an article published in}

Spieldenner, A.R. \& Glenn, C.L. (2014). Scripting hate crimes: Victim, space and perpetrator defining hate, Continuum: Journal of Media \& Cultural Studies, 28(1), 123-135. doi: 10.1080/10304312.2013.854873

as published in the Continuum: Journal of Media \& Cultural Studies 2014 [copyright Taylor \& Francis], available online at: http://www.tandfonline.com/10.1080/10304312.2013.854873

\section{Abstract:}

Hate crime legislation is meant to address discrimination at a community level. The hate crime categorization involves the justice system and the media - who play a key role in the community's understanding of the act. In 2008 in Washington, DC, two separate attacks on gay men - one White, one African-American - were categorized differently. One was a hate crime; the other was not. This paper looks at the social scripts employed within the media and police statements that contextualize these events in terms of neighbourhood as well as the race, gender and sexuality of the victims and perpetrators.

Keywords: Media | Hate Crimes | Gender | Race | Sexuality

\section{Article:}

In the United States capitol, the District of Columbia, the press labelled two separate crimes as hate crimes in the fall of 2008 with very different prosecutorial outcomes. Within a month, two gay men were attacked in the streets after hours near nightclubs - one a Black gay man, the other a White gay man. The incidents involved Black assailants who spouted homophobic epithets during the violent attacks. In one, the (Black) victim was robbed and killed; in the other, the (White) victim was knocked unconscious. The Black perpetrators were also different: with the Black victim, the perpetrator is another African-American man; with the White victim, the perpetrators are two Muslim African immigrants. Curiously, the judicial system did not label the robbery/murder a hate crime, yet did categorize the assault as one. In observing both media and judicial practices concerning the two cases, the differences in the events seem to be central in the construction of the hate crime designation. The victims and the neighbourhoods become part of the rhetoric determining the nature of the crime.

The term 'hate crimes' refers specifically to criminal acts rooted in or augmented by identity differentials such as ability, gender, race, age and sexuality. This legislation is specifically meant to deter bias crimes from happening by identifying them as hate crimes and enhancing punishment guidelines. While hate crimes may be a legal construct, it is a term used by the 
media and within the vernacular to describe events. In her research on hate crimes, Mason points out that, 'Hate crimes laws are an interesting example of how harsher forms of punishment may be deployed in the name of social justice' (2009, 276). In the two cases analysed in this project, the term 'hate crime' is employed quite differently. When conducting an analysis of how these events are constructed as rhetorical events in the media, we aim to understand what factors play a role in defining the 'hate crime'.

Cultural and critical studies have a place in the examination of human rights and social justice. While these areas are the primary concern for community groups, governmental agencies and other academic disciplines (like legal studies, political science, social work and sociology), there remains some concern about how a cultural studies and critical approach would engage these areas (Coombe 2010). We would argue that cultural and critical approaches are useful tools in looking at real-world cases to examine power and multiple identity lenses. Gies asserts that 'the media distort people's understanding of the law ... audiences are almost by default overly media dependent because they lack any relevant first-hand legal experience with which to offset distorted media representations' (2005, 171). For this project, we employed media reports, interviews with the victims, statements made by the police and government statistical data to interpret the possible factors interpreting the events.

\section{Constituting hate}

Legislation concerning hate crimes carries particular importance to marginalized communities. The protected classes in current hate crime statutes - race, ethnicity, age, sex, sexuality, gender identity and political affiliation - are conceptually part of socially disenfranchised groups in the United States. This disenfranchisement is personal as well as institutional, and has historically resulted in discrimination, stigmatization and violence. Hate crime legislation is a social pact between larger mainstream society and the marginal group, and can therefore signify some form of institutional acceptance (Moran 2004).

Hate crime statutes have been passed in 45 states and the District of Columbia (Anti-Defamation League 2006). In the nation's capitol, the hate crime law is referred to as 'The Bias-Related Crime Act of 1989' (DC Code $\S \S 22-4001$ to 22-4004) and includes protection on the basis of perceived race, colour, religion, national origin, sex, age, marital status, personal appearance, sexual orientation, family responsibility, physical handicap, matriculation or political affiliation. These statutes specify that crimes against and motivated by the protected class of identity will have enhanced sentencing at conviction. While all of these cover race and ethnicity as protected classes, only 32 include sexual orientation and disability and 28 include gender. A meagre 13 protect age, 11 include transgender or gender identity, and 5 allow political affiliation as a class. Hate crimes, also known as bias crimes, are not part of any federal acts, but the Federal Bureau of Investigation does collect statistics on victim and perpetrator demographics, as well as reported bias-motivations. 
The American Civil Liberties Union (ACLU) points out that, without federal provisions, criminal prosecution is left up to local and state jurisdictions (ACLU 2007). In some crimes, the local police may not investigate certain crimes due to their own biases or beliefs about certain groups - in fact, they may not identify the event as a crime. In testimony to the United States House of Representatives, the ACLU pointed out several cases of rape, assault, harassment and murder that were left uninvestigated by local law enforcement. As Mason points out, 'the question of which groups are publicly recognised as the bona fide victims of hate crime, or given 'protected status' under the hate crime law is far from an objective one' (2007, 251). Public outcry can play a key role in constructing the crime as a 'hate crime' through the insistence that the victim's identity is protected, and that law enforcement and the justice system have an obligation to intervene.

The seriousness of the crime in the United States is determined by both the wrongfulness of the act and the culpability of the perpetrator (Harel and Parchomovsky 1999). Hate crime legislation does identify some motivations and actions as more morally wrong, in terms of the act itself and individual accountability. Mason asserts,

the capacity of victim groups to contribute to the moral claims embodied in the concept of hate crime, and thereby be accorded victim status, is shaped in part by our emotional responses to those groups and their demands for social justice'. (2007, 251)

Unfortunately, identifying prejudice in an act is often left up to the criminal offender. State of mind is evidenced through confession and testimony. This focus 'seems to facilitate a dual concern for both the perpetrator of the crime (via its emphasis on culpability) and the victim (via its emphasis on wrongfulness)' (Harel and Parchomovsky 1999, 520). The government's concern with social equality is not part of the definition.

Bias crime statutes are based in the belief that additional punishment is required to deter future crimes, either by the initial perpetrator or by other like-minded individuals in the community. The United States is ostensibly a nation of people from various migration routes and histories and, in the post-Civil Rights era, with equal rights. Therefore, crimes based on difference are considered particularly heinous and media noteworthy (Bittle 2002). Proponents of hate crime legislation believe that enhanced punishment works towards social equality by deterring crime. Hate crime designation is also seen as a way to close holes in existing judicial system procedures and out-of-date sentencing guidelines (Adams 2005). In this view, a crime is a crime, regardless of the motivation. The problem lies not with the victim or the motivation, but the acts.

Media coverage of hate crimes is a key part of the community understanding of the event (Bittle 2002, 48). There are considerable differences in framing, depending on outlet and distribution audience. A local newspaper may portray the crime and its victim as less sympathetic than a national news agency (Husselbee and Elliott 2002). Similarly, media outlets that service particular constituents may focus on a shared identity characteristic. Whether a news 
outlet chooses to ascribe blame to the victim or to the perpetrator does affect the audience understanding of the crime as a bias crime (Quist and Wiegand 2002, 103). The community becomes an important actor in organizing around the crime, its victims, law enforcement and the criminal justice system.

Hate crime legislation seems to rest on the rhetorical assumption that some violent crimes those that are based on personal characteristics of the victim and fuelled by some discriminatory power - deserve harsher punishment. Most acts determined today as 'human rights' are positioned as a 'selective tolerance of difference' through their inconsistent standards and irregular implementation (Hawes 2010, 268). The lack of consistency in protected classes in bias crimes is itself a complication. While race and ethnicity are covered in each of the legislative statutes, other identities are not. In one case, the killer of an African-American gay man attempted to appeal the hate crime designation of his conviction because 'the evidence established, if anything, that he beat [the victim] because he believed him to be a homosexual and not because he was Black' (ACLU 2007). The rhetorical construction has deep implications on the cultural construct of the terms: hate, crime and identity. In this case, the state prosecutor pointed out that the perpetrator had let a White gay man escape, and focused the violence on the African-American gay male victim. The media - in terms of community papers, university papers, large local papers and local news affiliates - play an integral role in crafting messages and social scripts, as well as providing public voice on these issues.

\section{Identity, difference and scripting}

Social scripts are a useful way to explore social interactions. As a concept, social scripts have been developed in various social sciences, and describe rules that interactants understand and follow; they provide clues for behavioural norms, responses and cultural frames (Parker 2010). Social scripts have been used to research - amongst other areas - intercultural communication, management technique in organizations and conflict studies (Avery et al. 2009). Scripts rely on the understanding of situational norms for identities.

History and popular media fuel concepts of identity norms. Knowing the identity norm, and practising it, dynamically involves the individual (through actions and beliefs) and the larger society (through community interaction or media portrayal). Borrowing from sociology and theatre, Jackson calls this practice scripting, where the body both is and carries the text (2006). The social activity of scripting 'someone else's body is to actively inscribe or figuratively place one's self, worldview, or ascriptions onto another projected text, which often requires dislocating the original text and redefining the newly affected or mirrored text as the counterpositional or oppositional Other' (Jackson 2006, 53). Scripts are knowable, performed and restricted. These scripts become the shorthand to interpret an event (Jackson2006, 58-59).

African-American men have particular scripts in the United States. Jackson identifies these as: exotic and strange; violent; incompetent and uneducated; sexual; exploitable; and innately 
incapacitated (Jackson 2006, 75). The scripts are historically rooted racial projections onto the Black male body. Regardless of whether an individual expresses or experiences any of these conditions, they remain part of the text that surrounds them. These scripts become the lenses that interpret African-American men's actions (Jackson 2006, 99). Therefore, regardless of an African-American man's purpose or capacity, he will likely be perceived as an outsider ('exotic and strange'), aggressive ('violent' and 'sexual'), or unskilled and ignorant ('incompetent and educated', 'exploitable' and 'innately incapacitated').

The media articulates mainstream norms about identity: often ones that can be limiting in scope. Harper criticizes the front-page New York Times Magazine article 'When plagues end' by Andrew Sullivan for its tendency to mainstream the gay experience in America (1997). Sullivan insists that mainstream America has a home for gay men, one where gay men live as publicly open and in normative ways (e.g. single partner domesticity, capital consumption, performing hegemonic masculinity) (Harper 1997, 10-12). Politicized as a Black gay man, Harper finds himself outside of Sullivan's assimilationist rhetoric and, as such, cannot be interpellated as a subject within it (Harper 1997, 18). Harper notes the similarity in the rise of homeless people in the United States and their concurrent economies (transforming begging to selling newspapers, for instance) (1997, 25). This forces a visibility on the largely invisible. Rather than causing massive acceptance, homeless people are again demonized in the press as visible targets, obstacles to traffic in everyday living for 'normal' people. Ironically, while walking with his partner in New York's Village, Harper finds himself as part of a conversation with a homeless man who wonders why the couple is not holding hands. The experience shows how those outside normative discourses can engage in rhetorical practices that interpellate their subjectivity in positive ways. Harper points to the exclusionary practices that normativity entails and the complicated ways that this norm is promoted.

\section{Disciplining masculine bodies}

Foucault posits that social norms create processes that serve to both discipline and punish difference (Foucault1977/1995, 182-183). Discipline relies on a system of surveillance and enforced order. Punishment occurs as threat and actual punitive measures when social norms are violated. Through these two interactive processes, social norms are maintained and reified. Individuals choose to subscribe to the norm in order to avoid disciplining and punishing actions. All parts of a society have norms that are presented as unassailable truths - even how people act as men or women, how sexuality is expressed and even who is marked as an outsider or insider.

Gender, the determination of what is masculine or feminine, is not technically tied to biological sex or even an index of physicality. Butler problematizes these relations by asking:

Is 'the body' or 'the sexed body' the firm foundation on which gender and systems of compulsory sexuality operate? Or is 'the body' shaped by political forces with strategic interests in keeping that body bounded and constituted by the markers of sex? (Butler 1990, 175) 
The body is defined as masculine or feminine - even gay or straight - within multiply indexed moments crafted between cultural and institutional schemes.

Trying to define the limits of these schemes is perhaps most evident in analysing specific moments. Sloop calls attention to 'cases of "marginalized" identities ... existing publicity is even more important in providing individuals with ways to understand their own subjectivity' (2004, 21). By exploring specific moments where the body - sexed, gendered, raced and sexualized - is situated, the mechanisms of control and rewards are made transparent. By adhering to gender and sexual norms, the individual avoids disciplinary action. This punishment is enacted through other people, institutions, media, sex practice and even family. Normative behaviour is rewarded as another method of control; the process of fitting in is considered a benefit socially.

Physical violence is perhaps the most heinous example of punishing those who deviate from the heterosexual norm. Although homophobic violence is not new, the media attention in recent decades has provided movement and attention on policy changes to address this phenomenon from cultural, institutional, legal and social frameworks. Hate crime legislation has been one tactic towards social justice.

\section{The two cases: Tony Randolph Hunter and 'David'}

This project looks specifically at the media coverage and legal outcomes of two cases of homophobic violence that occurred in the United States capitol Washington, DC, in 2008. In the cases, the different media frames and differential legal outcomes are centred on the social norms. Through these two examples, the race, gender, sexual and neighbourhood schemes - as well as their potential impact - become more pronounced. The two cases are selected because of their proximity in terms of time (they occur within a month of each other) and space (within the same city). If those elements are the same, then what makes each case different?

On 7 September 2008, Tony Randolph Hunter and his friend - both African-American gay men - were in the proximity of a gay club in the Shaw neighbourhood in the District of Columbia. Hunter had an altercation with a group of African-American youth, while his friend fled the scene. The Washington Blade, a gay newspaper, reported that police, missing his wallet, had found Hunter, a native of Maryland, in a coma on the sidewalk. Ten days after the attack, Hunter died while still in a coma (Chibbaro 2008a). The police arrested 18-year-old African-American Robert Hannah, a local resident, for the crime. Although initial media reports allege Hannah used homophobic slurs during the attack, the courts did not see the event as a hate crime. In fact, the police investigation found Hannah culpable only for the beating - not the theft or the hate crime. Fox 5 News reported that Hannah testified that Hunter propositioned him in front of his friends with lewd grabbing, embarrassing him, and thus initiating the fight (2008). Although The Washington Blade refuted the allegation with testimony from Hunter's friends praising him as church going and unlikely to solicit a strange young man on the street, the paper also reported that Hannah and other witnesses described Hunter as intoxicated (Chibbaro 2008a). 
In the second case, on 3 October 2008, Georgetown medical student 'David' (an alias given to him by the press) left a nightclub with an unidentified male companion in Georgetown. According to an interview in The Washington Blade's interview of 'David', the two sat near two African men who were drinking out of a liquor bottle on the street and smoking some unidentified substance. When questioned about their sexuality, David admitted he and his companion were gay. The other men became volatile, invoking the Quran, insulting David and his friend, and in the end, hitting David over the head with the liquor bottle, leaving him unconscious on the street. His two assailants are identified as 22-year-old African immigrants Saad Elarch and 19-year-old Ruddard Abdulgadar (Lynsen 2008).

\section{Perception and prosecution}

The media serves multiple roles in perception of hate crimes - including acting as the voice for the legal system, larger social norms or the community's view. The media frames the perpetrator, the victim and the police actions for the public (Bittle 2002, 48-49). In these two cases, the media acts as the voice of the legal system and the interpreter for the public. As such, some of the depictions must be understood as a choice of the journalists and editors. The two cases were covered in The Washington Blade, The Washington Post, Georgetown Voice and local broadcast news affiliates of $A B C$ and Fox. Even with this diversity of outlets, the coverage remained consistent, regardless of where it emerged.

In the case of Tony Randolph Hunter, the prosecutor did not seek hate crime penalty enhancement, partially due to Hannah's alleged neighbourhood gang connection - which repositioned the crime from bias to gang-related. The presiding judge reduced Hannah's charge from voluntary manslaughter to involuntary manslaughter after hearing testimony from Hannah and his friends that Hunter allegedly made sexual advances on Hannah. The robbery charge was dropped completely, although Hunter's wallet remained missing. Hunter's companion was not called to testify. In addition, Hannah was released to a halfway house pending trial (Chibbaro 2008b).

In the coverage on Fox and $A B C$ local affiliates, Hunter is counter-positioned from victim to participant in the crime. He is identified as drunk and sexually aggressive towards the 18-yearold. Since these local media affiliates highlight the conflict, both actors are cast as violent unsurprising, considering those social scripts operating on Black men's bodies. Oddly, the perpetrator, victim and even the victim's friend are all clearly and equally identified by name and picture. This flattening of identifiers connotes equal participation in the event. In addition, the location of the crime - District One in the District of Columbia - is referenced in the media coverage leading to a larger context to defining the event. Hunter is identified as coming in from Maryland, and Hannah is a local. The event is labelled a hate crime by the gay media coverage, but not by other media or the police. 
In the case of 'David', $A B C$ News coverage of the event identifies the attack in Georgetown as a hate crime. The victims are an unnamed Georgetown medical student and a male friend who were 'accosted for being gay' by two Muslim men drinking vodka. In addition, the two perpetrators are identified by name, immigrant status and Muslim background. Considering the current anti-immigrant and anti-Muslim perception in the United States (Ali 2012), these identifiers enhance the perception of violence, and are integral to framing the interpretation of the acts. The police identified the event as a hate crime, and the presiding judge held the two men without bond because of the 'degree of depravity and danger' (ABC 7 News 2008). Abdulgadar plead guilty to the crime and faces up to five years in prison under hate crime enhancement (Chibbaro 2008c). In addition, the District Attorney requested deportation proceedings for both assailants after imprisonment.

The coverage maintains the anonymity of the victim. It situates 'David' within the community of Georgetown as a resident and student at a prestigious medical school. The attackers are identified by full name, age, religion and birthplace. In addition, the perpetrators are described as drunken, violent and smoking some unknown substance. 'David', on the other hand, wonders how people could target him and his friend since he did not cast aspersions on the attackers for being Black, Muslim or heterosexual. In addition, 'David' asserts that he and his friend were not overtly engaged in homosexual acts like (in his words) 'holding hands' (Lynsen 2008). 'David' is permitted to be a victim in the event and control his 'outness' as a gay man - his event is labelled as a hate crime by the media and police.

While the two cases occur within weeks of each other in the same city, they are depicted in different ways by the media and understood by the police as two unrelated events. One of the victims is African-American, while the other is racially unidentified. Often in United States communication, when race is not disclosed, it is assumed to be White (Nakayama and Martin 2007, 111-115). One of the events occurs in the Shaw neighbourhood, the other in Georgetown - these neighbourhoods have distinctive characteristics and racial narratives. One of the victims is dead and disparaged by his attacker as partly culpable for the crime; the other victim testifies to his innocence and normative behaviours. One of the victims is named (and thus revealed as a gay man); the other maintains anonymity. Each of these differences becomes part of the way that we understand the occurrence and severity of the crime.

\section{Construction of a crime: victim and location}

The two neighbourhoods where the events took place - Georgetown and Shaw - have distinct histories and racial demographics. In the District of Columbia, Georgetown is predominately White, while Shaw is a historically Black neighbourhood. Georgetown is unique in being the one neighbourhood without direct access through the city's rail system, limiting its accessibility and furthering the perception that it is removed from the District of Columbia. Shaw, on the other hand, has three stops along two of the District of Columbia's rail system, and is a major thoroughfare of buses. Both neighbourhoods are home to major universities: Georgetown has the 
prestigious Jesuit school Georgetown University; and Shaw is home to the largest historically Black college and university in the United States Howard University.

Race and neighbourhood complicate identity in interesting ways. The Black male body is scripted differently than White or other males, replete with a whole other set of expectations and norms. Unlike 'David', Hunter - the victim in the Shaw neighbourhood crime - is not permitted to be a victim. While Hunter is cast in Fox and $A B C$ local news as first the victim, he is then portrayed as the sexual aggressor to Hannah in subsequent newscasts. In the first broadcasts, Hannah is seen as a violent gangster, and then a victim to Hunter's perversions. This is integral to understanding the interpretation of the crime. In her analysis of the 'gay gang murders', Davis states, 'perpetrators' construction as "gang members" served to further locate them within discourses of criminality, monstrosity, and beastiality' (2007, 503). As Hannah shifts from gang member to victim, the crime shifts from a discourse about Hannah as menacing to Hannah as sexual victim to Hunter. The assailants of 'David' are cast within The Washington Blade and Georgetown press as Muslim, 'smoking a mysterious substance' and foreign (Chibbaro 2008c). The media scripting remains consistent concerning each of the Black men involved: sexually aggressive, deviant and outsiders, ineffectual and incapable, and violent.

Different neighbourhoods and spaces contain codes that identify socio-economic, racial, ethnic and gender norms. A business office and a party, for instance, would require various dress codes and mannerisms to 'fit in'. In a similar sense, the neighbourhood is similarly scripted. In some neighbourhoods, gay men and lesbians are more the norm than in other places (Chauncey 1995, 227-270). In this case, the Shaw neighbourhood is slowly being gentrified. In Shaw, there is an emerging racially diverse gay and lesbian population. Historically, Shaw has been one of the poorer neighbourhoods in the District of Columbia's northwest quarter. Georgetown is considered affluent, and has a more visible presence of White gay and lesbian individuals.

Crime and violence can also be a norm depending on the history and other social conditions (including the presence of law enforcement). According to District of Columbia Metropolitan Police reports, the neighbourhoods have vastly different crime rates. Shaw is in District One and, as of September 2008, the area reported 11 homicides and 331 assaults with a deadly weapon for the 2008 year ('Metropolitan Police Department' 2009a). Georgetown is in District Two and, as of September in the same year, the area reported 3 homicides and 137 assaults with a deadly weapon for the 2008 year ('Metropolitan Police Department' 2009b). The context of these events situates one as a typical crime in the neighbourhood, and the other as atypical for the neighbourhood. The judicial system - as represented by the judge and prosecuting attorney identifies Hunter's assault and death as unacceptable, but understandable within the domains of Shaw: the judge and prosecuting attorney do not pursue hate crime enhancement in the case of Hannah. The attack on 'David' is considered depraved and dangerous in the judge's statements to the media, which makes sense in the context of the relatively low crime rates of Georgetown. 
The neighbourhoods play a role in the social scripts. Georgetown is considered an affluent and racially less diverse with a high proportion of White residents in Washington, DC, whereas the Shaw neighbourhood is historically African-American and is only recently part of the District of Columbia's gentrification efforts. As such, Shaw has a far more diverse socio-economic range than Georgetown, and remains majority Black. The differential crime rates underscores these, as violence and crime is considered more normative than in the other, even by the agents of the criminal justice system - such as the judge and police. Law enforcement forces play a key part as the surveillance arm of disciplining society, and the judge is a core player in punishment, as Foucault frames it, by deciding sentencing. Through the two arms, the overarching discourse is able to force behaviours, conditions and expected outcomes within the community. The differing norms in each neighbourhood cue the police how and what to enforce.

\section{Scripting the body}

Scripts play a key role in interpreting each man's body. These provide the social schema as to the norms and expectations that the participants, media and law enforcement use to determine who acted in what capacity. Each participant seems to act, respond, understand and are understood through the lenses that frame their bodies. As such, we need to understand the many ways that these men are scripted - by context, race, sexuality and anonymity.

These men's bodies are also scripted by sexuality. When asked, 'David' openly discloses his sexuality to the two assailants - thus indicating his comfort being out as a gay man in Georgetown. Hunter is leaving a gay bar in the Shaw neighbourhood, giving some indication to those watching that he is a gay man. The disclosure of sexuality is apparently the catalyst to the Georgetown assault; in Shaw, the sexuality seems to serve as a trigger to escalate a robbery into a murderous beating. In the aftermath of the crimes, sexuality remains important. 'David' employs sexuality as a means to organize gay media outlets - giving repeated interviews to the District's leading gay print newspaper, the Blade. His sexuality is also used in the Georgetown University student paper to radicalize the community into action. On the other hand, Hunter's sexuality becomes part of the problem. Hannah and his attorney portray Tony Hunter in the media as sexually aggressive to his young assailant, brazenly grabbing Hannah on the buttocks and genitalia on the street. In their research on large-scale lesbian and gay community events, Tomsen and Markwell assert, 'varied homo and hetero-erotic pleasures of this event are both feared and desired by observers' $(2009,209)$. As a Black gay man, Hunter is understood within a larger range of framework of Black gay male images. Black gay men are often seen as sexually obsessed and sexually exotic within a framework of socio-economics, sexuality and pornography, regardless of the purported intent of the individual Black man (Harris 2008, 1020).

Anonymity is only granted to 'David'. In this way, he still has the agency to disclose or conceal his sexuality with the public, his educational institution and amongst his family. Hunter is not given this right. His picture appears on the front page of the Blade and alongside articles in 
the Washington Post. Whether Hunter was out as a gay man to his family, job and friends or not, his identity is broadcast through the media coverage. He is 'outed' as part of the process of the justice system. Being 'outed' denies the person the choice of disclosure; when that identity is stigmatized (as homosexuality remains), the media disclosure could trouble the professional, familial and social relations (Howard 2012, 130-132). Because he did not survive his attack, Hunter does not even control how he is remembered. While the law is not concerned with protecting the future rights of the deceased, the media's coverage - and the provision of anonymity - is integral to this discussion. The media determines that Hunter can be revealed. Without any portrayal of interviews with the family, the public is left without the knowledge of whether Hunter was out to them.

Race is part of how the two victims differ. Hunter is clearly African-American. 'David', on the other hand, is consistently anonymous, even racially. In the absence of racial marking, the default racial identity is White in the United States. Racial scripts are complex, often framing the interactions with prior experience and lessons gleaned from others ('I heard from a friend ...'). Race becomes a marker for our expectations and interpretation. 'David's' apparent Whiteness is part of his encounter with his assailants. He is comfortable approaching two Black men to solicit them for drugs in Georgetown after the bars close. His race grants him the entitlement in Georgetown to make contact with anyone.

Hunter's picture indicates he is Black, thus sharing a racial identity with Hannah - but the implications of the shared racial identity is not part of the media discourse. As Black men, Hunter and Hannah are situated within a complicated frame of race and masculinity. Since masculinity is performed, we can only infer from media typology of the two men. Hannah is identified as someone with gang ties and past criminal experience. These two factors imply that Hannah's masculinity is hard, able to fit in with other young urban men and potentially violent. Hunter, on the other hand, is only identified by his exit from a gay bar, his drunkenness and his friend abandoning him. Through Jackson's view of African-American masculinity, Hunter is scripted as a weak, ineffectual, even bumbling. In addition, we see Hunter and Hannah's interaction within the backdrop of the rise of the Black bisexual 'down low' myth in popular culture. In popular culture, 'down low' men are those who practice homosexual sex but identify publicly (and in some cases, psychologically) as heterosexual men. The 'down low' casts hypermasculine men as potential sexual objects and participants in homosexual sex (McCune 2008, 299-304). Within the Black community, this hyper-masculinity is often typified by athletics, hiphop or connections to gangs or other street crime (Jackson 2006, 107-109). Hunter, therefore, is either: sexually obsessed, believing in the myth of the down-low hidden bisexuality potential in the young man, or both.

The context provides clues as to who is considered local and who is not. Within Georgetown's homogeny, the two African assailants stand out as alien. 'David' describes them as mysterious figures in the night and smoking some unidentified strange substance: they do not belong in Georgetown. In all media interviews, 'David' is a sympathetic victim who was stumbling home. 
He is a successful medical school student at a prestigious private institution. The assault acts as an invasion on his body, and by extent, the wider body of Georgetown from the Muslim immigrants smoking an 'unknown substance'. This juxtaposition reifies David as familiar and somehow normal. Hunter, on the other hand, is identified as a Maryland resident coming into Shaw to go to a gay bar. He emerges from the bar drunk and somehow begins interacting with Hannah. In the narrative provided by Hannah and his attorney, this interaction was sexually aggressive on the part of Hunter. The assailant is defined as a local, as if Hannah is somehow defending his home neighbourhood from the invading homosexual.

The body is the place where this crime is acted out. Both assailants interpret their role - and their victim's role - through their homophobia. Hunter and 'David' are both attacked for being gay. 'David' is a medical school student at Georgetown and comfortable in a gay bar. The lack of a racial identifier would seem to indicate that 'David' is White, especially as his assailants are identified by religion, race and country of origin. The Georgetown assailants are African and Muslim, and cited as having quoted the Quran during the assault. Tony Hunter, on the other hand, has a picture on the front page of multiple papers identifying him as a Black gay man, murdered outside of a gay bar. The sensationalist aspects of these headlines aside, Hunter is clearly labelled within domains of his race, sexuality and gender. Tony Hunter's assailant is, like him, another African-American man. The similarity in race and gender between victim and perpetrator in the Shaw neighbourhood is not an unfamiliar narrative in the media or popular culture: Black on Black crime.

\section{Conclusions}

The two cases have very different prosecutorial outcomes. For the murder of Tony Hunter, Robert Hannah served six months in jail. For the assault on 'David', the assailants were sentenced in 2009 for three years in prison, and the United States Department of Homeland Security has initiated deportation procedures. The classification of the crime as a hate crime seems to both satisfy the community need for closure and enhance the sentencing. The disciplining force of law enforcement operates on multiple levels when invoked with the 'hate' designation. When the hate crime designation is not present, the penalty enhancement meant to disrupt these persistent criminal cycles is unavailable. In the case of Robert Hannah, his cycle continues. In 2011, Robert Hannah was arrested for attempted murder of his girlfriend, and his defence remains that she 'started it' (Najafi 2011).

Neither crime is justified. We do not consider one as more serious than the other. Rather, we explore the similarities and differences that nuance each event's coverage. The media coverage surrounding the events may not determine the outcome of the events, but it is symptomatic of the construction in each event of the nature of the acts and the parties involved. In fact, the persistent use of expected scripts seems to indicate the importance of understanding these scripts as interpretive lenses in order to develop any discursive intrusion. 
The media portrayal relies almost exclusively on relying on traditional roles of the assailants, victims and neighbourhoods. The White victim's interactions are never questioned even though he admits to asking his assailants for illicit substances; instead, he is seen as a sympathetic player. The Black victim is cast in multiple roles - from hapless victim to lascivious homosexual - depending on who promotes the narrative. The Black assailants are interpreted in similarly odd manners: the Muslim Africans have acted in egregious and monstrous manners, whereas African-American Robert Hannah is seen first as a gang banger, than as a potential victim of unwanted homosexual advances.

Unfortunately, only one side of Tony Hunter's case will be heard in the media and within the judicial system. Tony Hunter's performance as a gay man is situated within his Black male identity in a predominately Black neighbourhood. Hunter is punished permanently for this trespass. Whereas 'David' is permitted to tell his story in repeated interviews, Hunter is silenced and his assailant, Hannah, is permitted to control the narrative of the night's events. We will never know what happened between Hannah and Hunter, only that it resulted in Hunter's death. What we do know is that Hannah, news outlets and the judicial system follow a trajectory that allows for victim to become culpable in the crime.

In order to unpack the rhetoric, we highlight the socio-historical factors and positions. Black men, in these events, are scripted in specific ways that limit the interpretation of their actions. The seeming conflict between the potential for being exotic, impaired, violent, exploitable or uneducated are fully realized in the media coverage of these two crimes. The analysis of these events is not simply an exercise in critical analysis; it is part of determining the ways that gender and sexual identity conflict, restrain and deny aspects of a home where that identity is safe, celebrated and makes sense. It provides a way of understanding how identity is practised, performed, valued and punished within bodies.

Critical and cultural studies can serve as discursive interventions within human rights discussions. In the cases of Tony Hunter and 'David', cultural and critical approaches enable an understanding that the victim, perpetrator and neighbourhood are part of the interpretation of the hate crime legislation. Through these lenses, we can problematize the outcomes when these factors are not adequately considered. Coombe posits that 'clearly human rights are the fulcrum of a pervasive, powerful and authoritative normative discourse that requires the same powerful instruments of analysis that a critical cultural studies brings to bear on other discourses' (2010, 235). The exploration of local incidents of hate crimes and other human rights violations through critical cultural studies approaches connects the material act, the legislative prosecution and the media depictions, regardless of the conflicts between these prospective poles.

Through the exploration of these crimes, we recognize that sexuality and race remain difficult to discern and analyse. In the context of hate crimes, these identity factors remain integral to understanding the crime and its subsequent prosecution. Media coverage and law enforcement seemed to collude in defining the two crimes separately. The label of 'hate crime' is assigned to 
'David', but not in the case of Tony Hunter. With the understanding that people perform, embody and utilize multiple racial, sexual, socio-economic and gendered positions within interactions, we posit that location also plays a part in legal and media intervention. The geography and its history frame the understanding of identity and interaction.

\section{References}

1. ABC 7 News. 2008, October 8. “Two Georgetown Students Target of Hate Crime.” Accessed December 1, 2008.http://www.wjla.com/news/stories/1008/559909.html.

2. Adams, David M.2005. "Punishing Hate and Achieving Equality.” Criminal Justice Ethics24 (1): 19-30.

3. Ali, Yaser. 2012. "Shariah and Citizenship: How Islamophobia Is Creating a Second-Class Citizenry in America.” California Law Review100 (4): 1027-1068.

4. American Civil Liberties Union. 2007. ACLU Statement on Hate Crimes Legislation before the Crime Subcommittee of the House Committee on the Judiciary. Accessed December 1, 2008.http://www.aclu.org/lgbt/discrim/29391leg20070417.html.

5. Anti-Defamation League. 2006. State Hate Crime Laws. Accessed December 1, 2008.http://www.adl.org/99hatecrime/state_hate_crime_laws.pdf.

6. Avery, Derek R., Michelle R.Hebl, Jennifer A.Richeson, and Nalini Ambady. 2009. “It Does Not Have to be Uncomfortable: The Role of Behavioral Scripts in Black-White Interracial Interactions.” Journal of Applied Psychology94 (6): 1382-1394.

7. Bittle, Steven. 2002. "Media Treatment of Hate as an Aggravating Circumstance for Sentencing: The Criminal Code Amendment and the Miloszewski Case.” Canadian Ethnic Studies Journal34 (1): 30-50.

8. Butler, Judith. 1990. Gender Trouble. New York: Routledge.

9. Chauncey, George. 1995. Gay New York: Gender, Urban Culture, and the Making of the Gay Male World, 1890-1940. New York: Basic Books.

10. Chibbaro, Lou, Jr. October 15, 2008a. “D.C. Police Make Arrest in Hunter Murder.” Washington Blade. Accessed December 1, 2008. http://www.washblade.com/thelatest/thelatest.cfm?blog_id = 21741 .

11. Chibbaro, Lou, Jr. 2008b, October 31. “Judge Reduces Charges in Gay Man's Death.” Washington Blade. Accessed December 1, 2008. http://www.washblade.com/2008/1031/news/localnews/13506.cfm. 
12. Chibbaro, Lou, Jr. 2008c, November 13. "Man Pleads Guilty in G'town Gay Bashing." The Washington Blade. Accessed December 1, 2008. http://www.washingtonblade.com/thelatest/thelatest.cfm?blog_id $=22388$.

13. Coombe, Rosemary J.2010. "Honing a Critical Cultural Study of Human Rights." Communication and Critical/Cultural Studies7 (3): 230-246.

14. Davis, Kristen. 2007. “The 'Bondi Boys' - Un/Australian?” Continuum: Journal of Media \& Cultural Studies21 (4): 501-510.

15. Foucault, Michel. 1977/1995. Translated by Alan Sheridan Discipline and Punish: The Birth of the Prison. New York: Vintage Books.

16. Fox 5 News. 2008, October 9. Possible Motive Revealed in High-Profile D.C. Murder. Accessed December 1, 2008.

http://www.myfoxdc.com/myfox/pages/News/Detail ?contentId = 7614320\&version = 2\&locale $=$ EN-US\&layoutCode $=$ TSTY\&pageId $=3.2 .1$.

17. Gies, Lieve. 2005. "Law as Popular Culture: Cross-disciplinary Encounters.” Continuum: Journal of Media \& Cultural Studies19 (2): 165-180.

18. Harel, Alon, and GideonParchomovsky. 1999. “On Hate and Equality.” Yale Law Journal109 (3): 507-539.

19. Harper, Phillip Brian. 1997. "Gay Male Identities, Personal Privacy, and Relations of Public Exchange: Notes on Directions for Queer Critique.” Social Text52/53: 5-29.

20. Harris, Keith Malone. 2008. Boys, Boyz, Bois: An Ethics of Black Masculinity in Film and Popular Culture. New York: Routledge.

21. Hawes, Leonard C.2010. "Human Rights and an Ethic of Truths: Pragmatic Dilemmas and Discursive Interventions.” Communication and Critical/Cultural Studies7 (3): 261-279.

22. Howard, Sheena C.2012. "Intercultural (Mis)Communication: Why Would You 'Out' Me in Class?” Sexuality \& Culture16 (2): 118-133.

23. Husselbee, L. Paul, and Larry Elliott. 2002. "Looking Beyond Hate: How National and Regional Newspapers Framed Hate Crimes in Jasper, Texas, and Laramie, Wyoming.” Journalism \& Mass Communication Quarterly79 (4): 833-853.

24. Jackson, Ronald, III. 2006. Scripting the Black Masculine Body: Identity, Discourse, and Racial Politics in Popular Media. Albany: State University of New York Press. 
25. Lynsen, Joshua J.2008, October 17. "Gay Victim Recalls Attack in Georgetown.” Washington Blade. Accessed December 1, 2008. http://www.washblade.com/2008/1017/news/localnews/13431.cfm.

26. Mason, Gail. 2007. "Hate Crime as a Moral Category: Lessons from the Snowtown Case." The Australian and New Zealand Journal of Criminology40 (3): 249-271.

27. Mason, Gail. 2009. “The Penal Politics of Hatred.” Australian and New Zealand Journal of Criminology42 (3): 275-286.

28. McCune, Jeffrey Q., Jr. 2008. “'Out' in the Club: The Down Low, Hip-Hop, and the Architexture of Black Masculinity.” Text and Performance Quarterly28 (3): 298-314.

29. Metropolitan Police Department. 2009a. Annual Report 2008. District of Columbia: Metropolitan Police Department.

30. Metropolitan Police Department. 2009b. Annual Report 2008. District of Columbia: Metropolitan Police Department.

31. Moran, Leslie J.2004. "The Emotional Dimensions of Lesbian and Gay Demands for Hate Crime Reform.” McGill Law Journal49 (4): 925-949.

32. Najafi, Yusef. 2011, July 1. "Hannah Arrested Again: Community Reacts to Robert Hannah, Involved in 2008 Murder of Gay Maryland Resident, up on Charges Again.” Metro Weekly. Accessed November 1, 2012.http://www.metroweekly.com/news/?ak = 6396.

33. Nakayama, Thomas K., and Judith N.Martin. 2007. "The 'White' Problem in Intercultural Communication Research and Pedagogy.” In Whiteness, Pedagogy, Performance: Dis/placing Race, edited by Leda M.Cooks, and Jennifer S.Simpson, 111-137. Lanham, MD: Lexington Books.

34. Parker, Richard. 2010. "Reinventing Sexual Scripts: Sexuality and Social Change in the Twenty-First Century.” Sexuality Research \& Social Policy7: 58-66.

35. Quist, Ryan M., and Douglas M. Wiegand. 2002. "Attributions of Hate: The Media's Causal Attributions of a Homophobic Murder.” American Behavioral Scientist46 (1): 93-107.

36. Sloop, John M.2004. Disciplining Gender, Rhetorics of Sex Identity in Contemporary US Culture. Amherst, MA: University of Massachusetts Press.

37. Tomsen, Stephen, and Kevin Markwell. 2009. "Violence, Cultural Display and the Suspension of Sexual Prejudice.” Sexuality \& Culture13 (4): 201-217. 